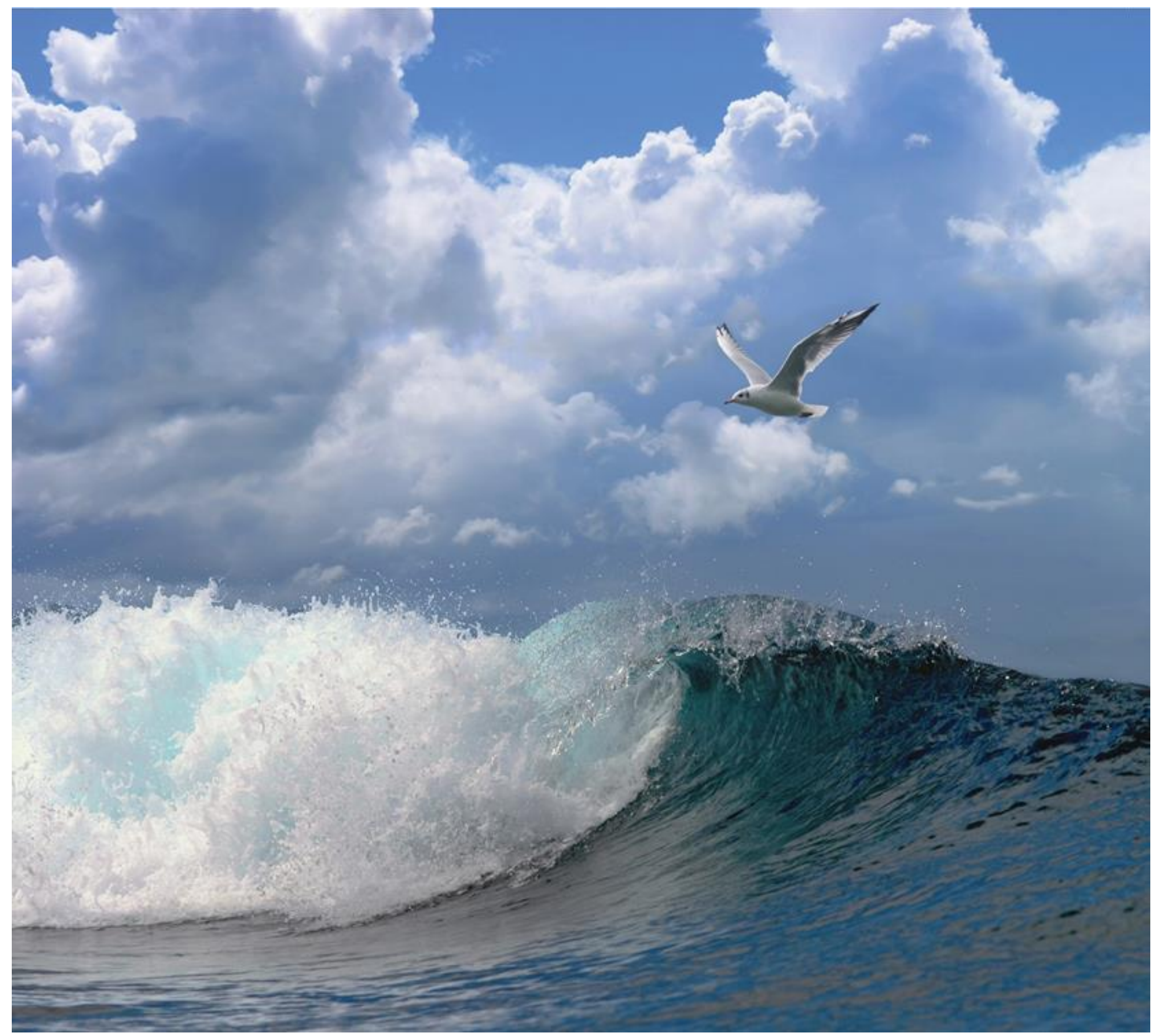

Bepaling van de larvendynamiek en mossel broedval bij de Noordzeeboerderij ten behoeve van optimalisatie oogstmoment zeewier 


\section{Bepaling van de larvendynamiek en mossel broedval bij de Noordzeeboerderij ten behoeve van optimalisatie oogstmoment zeewier}

\section{Publicatiedatum: December 2018}

Dit onderzoek is uitgevoerd door Wageningen Marine Research in opdracht van en gefinancierd door de Noordzeeboerderij en het Ministerie van Landbouw, Natuur en Visserij in het kader van het Maatschappelijk Innovatieprogramma 'PROSEAWEED' (projectnummer 43.181-001-75) 
Keywords: mosselkweek, zeewierteelt, broedval.

Opdrachtgever: Stichting Noordzeeboerderij

Zeestraat 84

2518 AD Den Haag

Dit rapport is gratis te downloaden van https://doi.org/10.18174/466266

Wageningen Marine Research verstrekt geen gedrukte exemplaren van rapporten.

Wageningen Marine Research Wageningen UR is ISO 9001:2015 gecertificeerd.

(C) 2016 Wageningen Marine Research Wageningen UR

Wageningen Marine Research, onderdeel van Stichting Wageningen Research KvK nr. 09098104,

IMARES BTW nr. NL 8113.83.696.B16

Code BIC/SWIFT address: RABONL2U

IBAN code: NL 73 RABO 0373599285
De Directie van Wageningen Marine Research is niet aansprakelijk voor gevolgschade, noch voor schade welke voortvloeit uit toepassingen van de resultaten van werkzaamheden of andere gegevens verkregen van Wageningen Marine Research opdrachtgever vrijwaart Wageningen Marine Research van aanspraken van derden in verband met deze toepassing.

Dit rapport is vervaardigd op verzoek van de opdrachtgever hierboven aangegeven en is zijn eigendom. Niets uit dit rapport mag weergegeven en/of gepubliceerd worden, gefotokopieerd of op enige andere manier gebruikt worden zonder schriftelijke toestemming van de opdrachtgever. 


\section{Inhoud}

Samenvatting

$1 \quad$ Inleiding \& Vraagstelling

2 Methoden $\quad 6$

3 Resultaten $\quad 7$

3.1 Abiotiek $\quad 7$

$\begin{array}{ll}3.2 & \text { Mossellarven en broedval }\end{array}$

4 Discussie $\quad 9$

$5 \quad$ Conclusie \& Aanbevelingen $\quad 10$

$\begin{array}{llr}6 & \text { Kwaliteitsborging } & 11\end{array}$

$\begin{array}{lr}\text { Literatuur } & 12\end{array}$

$\begin{array}{lr}\text { Verantwoording } & 13\end{array}$ 


\section{Samenvatting}

Zeewieren en schelpdieren komen vaak gezamenlijk voor in mariene kust ecosystemen en kunnen elkaar op verschillende manieren beïnvloeden. Zo kan de broedval van schelpdieren de oogst van zeewier (met name bruinwieren) beïnvloeden door middel van competitie om ruimte. In dit onderzoek inventariseren we of de broedval van mosselen een probleem kan vormen met betrekking tot competitie om ruimte voor commerciële zeewierteelt op de Noordzee. Oogst van bruinwieren en de broedval van mosselen vindt beide plaats in het voorjaar. Rekening houden met het moment waarop zeewier geoogst wordt en met het moment van de broedval van mosselen kan mogelijk een winst voor het zeewierproduct opleveren. De doelstelling van dit onderzoek is om voor de testlocatie 'Noordzeeboerderij' Scheveningen te bepalen wanneer de mossellarven in het water aanwezig zijn, en wanneer de broedval plaats vindt en of er een eventuele correlatie met broedvalmonitoring in de Oosterschelde en Noordzee is. In de periode van maart tot juli 2018 zijn regelmatig monsters genomen om larvenaantallen in het water te bepalen. Tevens zijn er collectoren uitgehangen om de broedval te bepalen. De piek van de larven abundantie was in week 15, en in week 29 werden de meeste mosselbroedjes op de collectoren waargenomen. Gezien de frequentie van monstername is het aan de hand van deze data niet mogelijk om exact te bepalen wanneer de larven in het water aanwezig waren en wanneer het broed zich gaat settelen. Vergelijking met data van locaties in de Oosterschelde en Waddenzee laat zien dat het moment van de larvenpiek en broedval per locatie en per jaar kan verschillen. Ook de hoeveelheid larven en broedval kan per jaar en locatie verschillen. Voor het afstemmen van het oogstmoment voor zeewier wordt op basis van deze gegevens een conservatieve aanpak geadviseerd met week 20 als uitgangspunt om te oogsten en zo eventuele aangroei en competitie met mosselen te voorkomen. Hogere frequentie van bemonstering over meerdere jaren kan een beter beeld geven van het aantal larven en het moment van broedval. Daarbij is het wenselijk te richten op het komen tot een correlatie met de broedval op de Noordzee en in bijvoorbeeld de Oosterschelde en de Waddenzee. 


\section{$1 \quad$ Inleiding \& Vraagstelling}

Naast de bestaande mosselkweek is er in Nederland ook steeds meer aandacht voor zeewierteelt. Zeewieren en schelpdieren komen vaak gezamenlijk voor in mariene kust ecosystemen en kunnen op hetzelfde substraat leven. Daarom wordt in het kader van offshore productie vaak gesproken over combinatieteelten van zeewier en mosselen, dit mede in het kader van multi-use met betrekking tot windparken. Voordelen van combinatieteelt zijn: (i) optimaliseren ruimtelijke benutting, (ii) gedeelde kosten voor gebruik verankering, lijnen en boeien en een (iii) grotere risicospreiding door "gewasdiversificatie". Zeewier en schelpdieren kunnen elkaar op verschillende manieren beïnvloeden, zoals bijvoorbeeld (i) door de concurrentie om beschikbare nutriënten tussen zeewier en fytoplankton (voer voor schelpdieren), (ii) de door schelpdier uitgescheiden nutriënten, specifiek ammonium $\left(\mathrm{NH}_{4}^{+}\right)$, kunnen opgenomen worden door zeewier, (iii) verbetering van doorzicht van het water door filtratie van schelpdieren kan leiden tot verhoogde zeewiergroei en (iv) broedval van schelpdieren kan de oogst van zeewier(met name bruinwieren omdat de broedval van mosselen en de oogst van bruinwieren beide in het voorjaar plaatsvinden) beïnvloeden.

Het huidige onderzoek richt zich op dit laatste aspect en hierbij inventariseren we of de broedval van schelpdieren een probleem kan vormen voor commerciële zeewierteelt op de Noordzee. Na een larvale fase in de waterkolom settelen schelpdier larven zich op substraat waarna ze zich, als de omstandigheden dit toelaten ontwikkelen tot volgroeide schelpdieren. Dit kan hard substraat zijn maar ook zeewierlijnen kunnen als substraat dienen voor schelpdierenbroed. Op deze manier kan er ruimtelijke concurrentie tussen zeewier en mosselbroed ontstaan op de lijnen. Schelpdieren kunnen ook het oogstproces bemoeilijken en/of effect hebben op de kwaliteit van het oogstbare zeewier, bijvoorbeeld door schade aan het zeewierblad vanwege frictie met mosselen. Ook kan het gewicht van de mosselen een extra belasting op de kweekconstructie vormen.

Oogst van bruinwieren en de broedval van mosselen vindt beide plaats in het voorjaar. Idealiter zou men het zeewier oogsten voordat vestiging van het mosselbroed problemen oplevert. Rekening houden met het moment van broedval van mosselen en het moment waarop zeewier geoogst wordt kan mogelijk een winst voor het zeewierproduct opleveren (zowel kwalitatief als het vereenvoudigen van het oogstproces). Het is daarom van belang om te bepalen wanneer mossellarven in het water komen en wanneer de broedval plaats vindt. Mosselen zijn in de Noordzee op talrijke harde substraten in de vorm van boeien, scheepswrakken, windmolens en boorplatforms te vinden (Coolen, 2017). Onderzoek heeft aangetoond dat mosselen in de gehele Noordzee aanwezig zijn en dat broedval plaatsvindt wanneer substraat aangeboden wordt (Kamermans et al., 2016). Een belangrijke parameter voor mosselen om zich voort te planten is de temperatuur van het water. Bij een sterke toename van de temperatuur zullen mosselen zich gaan voortplanten. In de Waddenzee en de Oosterschelde is die temperatuur meestal rond de $9^{\circ} \mathrm{C}$ (pers. com. J. Capelle). De doelstelling van dit onderzoek is om voor de testlocatie 'Noordzeeboerderij' Scheveningen te bepalen wanneer de mossellarven in het water aanwezig zijn, en wanneer de broedval plaats vindt. 


\section{Methoden}

Dit onderzoek is gebaseerd op methodes zoals toegepast voor mossellarventellingen en broedvalbepalingen in de Oosterschelde en de Waddenzee (Capelle, 2018). De offshore testlocatie 'Noordzeeboerderij' (NZB) Scheveningen bevindt zich $15 \mathrm{~km}$ uit de Nederlandse kust (NW: $4.0636^{\circ}$, $52.164^{\circ}$ ). Hier zijn gestandaardiseerde teeltmodules (SMAC- modules) uitgezet waarin in de periode December 2017 tot Juni 2018 suikerwier (Saccharina latissima) is gekweekt. Binnen deze modules zijn sinds begin maart (week 10) regelmatig watermonsters genomen om het aantal mossellarven in het water te bepalen. De frequentie van monstername is afgestemd met reguliere vaartrips naar de NZB (tabel 1), dit is minder frequent dan de wekelijkse bemonstering die plaats vindt in de Oosterschelde en de Waddenzee (Capelle, 2018). Voor het bepalen van het aantal mossellarven is 100 liter water gefiltreerd door een $55 \mu \mathrm{m}$ planktonnet waarna al het organisch materiaal uit het planktonnet verzameld is. De monsters zijn gekoeld bewaard en binnen 1-3 dagen naar het lab getransporteerd, waar het vervolgens is gefixeerd met $4 \%$ formaldehyde. In het lab is het aantal larven met behulp van een microscoop bepaald. In figuur 1 zijn mossellarven onder de microscoop te zien. Hiervoor is 3 keer een deelmonster van $2 \mathrm{ml}$ genomen en hierin zijn alle mossellarven geteld. Dit aantal is vervolgens vermenigvuldigd met het totale volume van het monster om het totaal aantal larven per $100 \mathrm{~L}$ te bepalen. Monsters zijn genomen in week 10, 12, 15, 18, 23, 29 en 34.

Vanaf week 12 zijn ook collectoren uitgehangen om de broedval te bepalen (zie tabel 1 voor periodes dat deze in het water gehangen hebben). Deze collectoren zijn vervolgens iedere keer dat de locatie bezocht werd vervangen voor een nieuwe collector, en de bemonsterde collector is gekoeld mee teruggenomen naar het lab. Eén additionele collector heeft de gehele periode van week 12 tot week 29 in het water gehangen.

Om de broedval te bepalen is een collector met een diameter van $15 \mathrm{~cm}$ opgehangen (voor beschrijving zie Capelle, 2018). Deze collector is voorzien van een gaas waar de mosselen zich op kunnen hechten (zie figuur 2). De collectoren zijn bevestigd aan de zeewierconstructie en werden +/$20 \mathrm{~cm}$ onder het water oppervlak geplaatst. Collectoren zijn verzameld in week 15, 18, 23 en 29 gekoeld bewaard en vervoerd. Met behulp van een binoculair zijn alle mosselbroedjes die zich op de collector bevonden geteld.

Daarnaast is de watertemperatuur gemeten met een temperatuursensor (HOBO UA-002-64). Deze is op 21 maart met duikers opgehangen aan een van de zeewierlijnen op dezelfde diepte als de broedval collector $(0.2 \mathrm{~m})$. Op 9 juni is de logger verwijderd en is de data uitgelezen. Deze loggermeet zowel temperatuur als licht. Licht is vooral van belang voor zeewiergroei, maar wordt ook opgenomen in deze rapportage om een beeld van de abiotische factoren in de omgeving te schetsen.

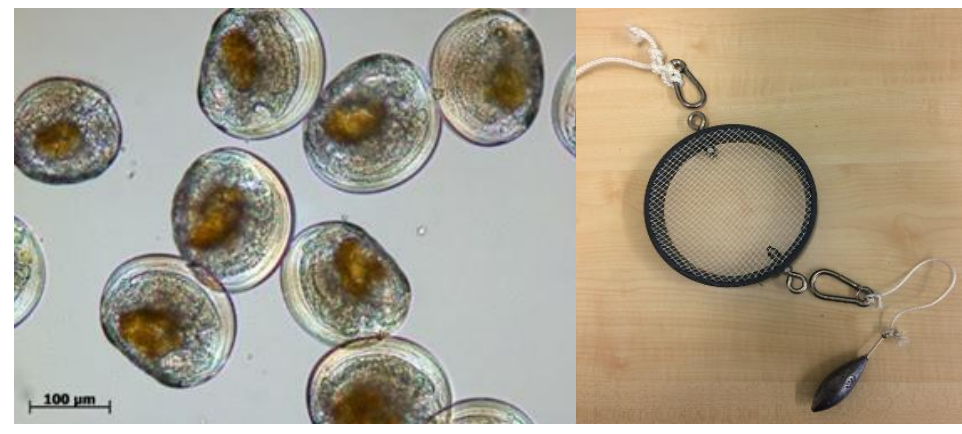

Figuur 1. Mossellarven onder een microscoop. Figuur 2. Broedval collector. 


\section{Resultaten}

\subsection{Abiotiek}

In figuur 3 is de temperatuur (graden Celsius) weergegeven over de periode 21 maart tot 9 juni. De temperatuur loopt op van 5 graden in maart tot 16 graden in juni, met uitschieters naar 20 graden. De temperatuur gemeten bij de Noordzeeboerderij is over het algemeen vergelijkbaar met de temperatuur gemeten op verschillende locaties in de Oosterschelde (Neeltje Jans, Vondeling) en de Waddenzee (Burgzand, Gat van Stompe, Zuidmeep) waar vergelijkbare monsters voor larven tellingen en broedval zijn genomen (Capelle, in press).

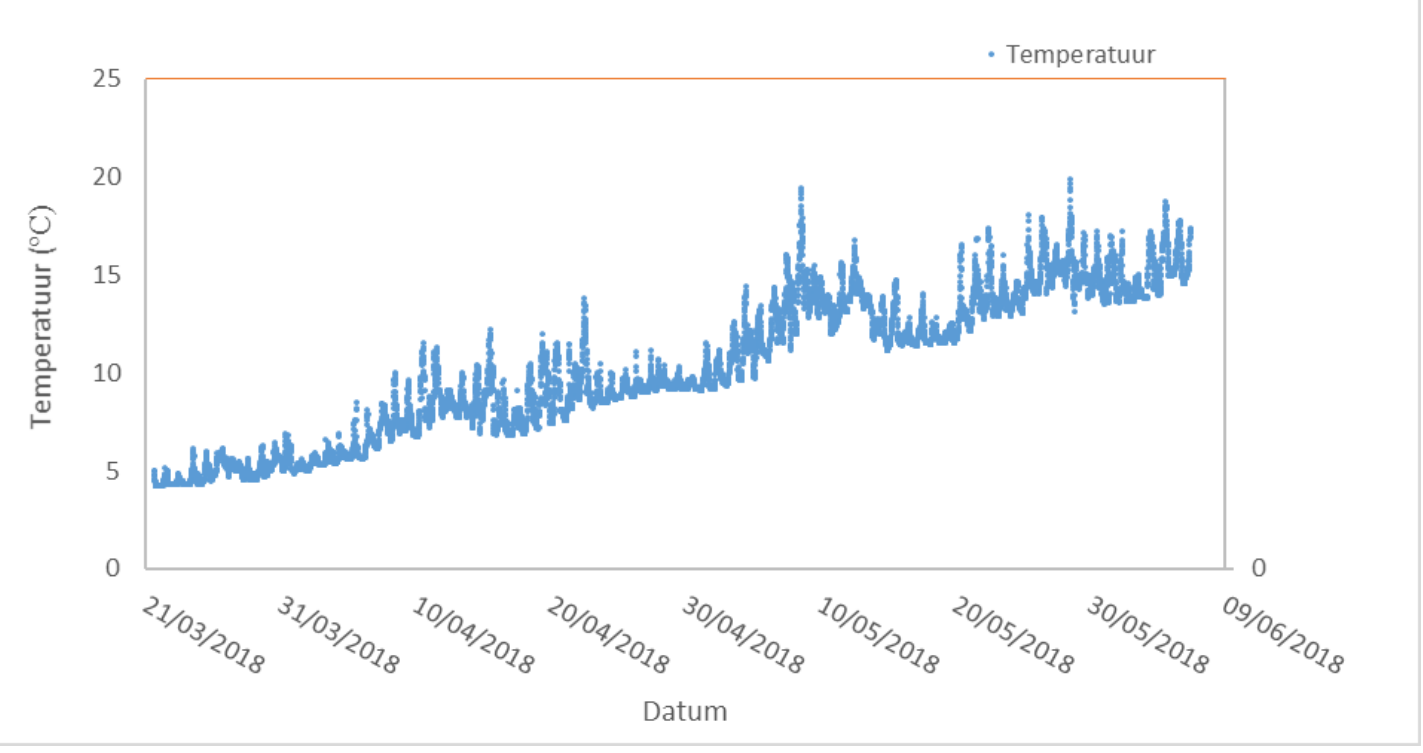

Figuur 3. Temperatuur bij de Noordzeeboerderij in de periode 21 maart tot 9 juni (meetinterval 30min).

\subsection{Mossellarven en broedval}

In tabel 1 zijn de abundantie van mossellarven en mosselbroedval weergegeven. Er zijn maximaal 176 larven per 100 liter en 32 broedjes per collector. Op de collector die gedurende de hele periode (data) heeft uitgehangen zijn 212 broedjes aangetroffen.

Tabel 1. Het aantal mossellarven per 100 liter en het aantal broedjes per collector per week aangetroffen bij de Noordzeeboerderij.

\begin{tabular}{|l|c|c|c|c|}
\hline Week & Datum & $\begin{array}{c}\text { Larven per } \\
100 \mathrm{~L}\end{array}$ & $\begin{array}{c}\text { broed op } \\
\text { collectoren }\end{array}$ & $\begin{array}{c}\text { Periode uithangen } \\
\text { collector (weken) }\end{array}$ \\
\hline 10 & $03 / 03 / 2018$ & 0 & & \\
\hline 12 & $21 / 03 / 2018$ & 0 & & 3 \\
\hline 15 & $13 / 04 / 2018$ & 176 & 0 & 3 \\
\hline 18 & $04 / 05 / 2018$ & 0 & 7 & 5 \\
\hline 23 & $06 / 06 / 2018$ & 51 & 32 & 6 \\
\hline 29 & $16 / 06 / 2018$ & 0 & & 17 \\
\hline 34 & $19 / 07 / 2018$ & 0 & 212 & \\
\hline Gehele periode & & & &
\end{tabular}


Van de meetmomenten was de piek van de larven abundantie in week 15, en de meeste mosselbroedjes werden op de collectoren waargenomen nadat deze een periode van 6 weken uithingen (in week 29). Gezien de onregelmatige frequentie van bemonsteren en de lange periodes tussen de monstermomenten is het aan de hand van deze data echter lastig om de larvendynamiek te bepalen en te bepalen wanneer het broed zich gaan settelen. Hierdoor is het enkel mogelijk een grove schatting te geven. Dezelfde analyses voor mossellarven en mosselbroedjes zijn in 2017 en 2018 (data 2018 nog niet beschikbaar) uitgevoerd in de Oosterschelde (twee locaties) en de Waddenzee (drie locaties) (Capelle et al., 2017). Uit deze gegevens blijkt dat het moment van de larvenpiek kan per locatie en per jaar verschillen. In 2017 viel de larvenpiek in de Oosterschelde eerder (rond week 14) dan in de Waddenzee (rond week 20) terwijl ze in 2018 beide rond week 17 en week 18 vielen. Ook was de piek in de Oosterschelde in 2018 een stuk hoger (rond 15000 larven/L) dan in de Waddenzee (rond 8000 larven/L) (pers. com. J. Capelle). De broedval lijkt in beide jaren wat eerder in de Oosterschelde te beginnen (week 19) dan in de Waddenzee (week 21). De broedval in de Waddenzee was in beide jaren laag (maximaal rond de 200 broedjes) vergeleken met de Oosterschelde (maximaal 1250 en 500 broedjes in respectievelijk 2017 en 2018)(pers. com. J. Capelle). 


\section{Discussie}

Het aantal larven in de waterkolom en de broedval zoals gemeten tijdens de huidige studie is gering ten opzichte van de Waddenzee en Oosterschelde. In vergelijking, in de Oosterschelde en Waddenzee zijn in deze periode (voorjaar 2018) dezelfde analyses uitgevoerd en hier zijn op sommige locaties tijdens de piek tot circa 15.000 larven per 100 liter gevonden (pers. com. J. Capelle). Dit kan deels door de lagere dichtheden van mosselen in de Noordzee komen, die zich daar voornamelijk op kunstmatige harde substraten hechten. Daarbij is het zo dat d de variatie in maximale waarden tussen locaties met name in de Waddenzee aanzienlijk was (4.500 -14.500 larven per 100 liter). Op de collectoren zijn circa 300 broedjes per collector aangetroffen, met uitzondering van Neeltje Jans waar maar 72 broedjes zijn waargenomen. De meeste broedval in 2018 vond in de Oosterschelde in week 24 plaats en in de Waddenzee viel deze piek wat eerder, over de periode tussen week 21 en week 23 (pers. com. J. Capelle). Ook eerdere resultaten geven het erratische optreden van natuurlijke zaadval aan (Capelle et al, 2017). Ondanks de lage larvenaantallen en broedval op de collectoren bij de Noordzeeboerderij, heeft er wel een behoorlijke broedval plaats gevonden. Tijdens duikinspecties van de zeewierlijnen op 19-07-2018 is op een zeewier lijn veel mosselbroed waargenomen (zie figuur 4). Een eventuele verklaring voor de erg lage aantallen van larven en broedval op de collectoren is dat de piek van mossellarven in het water gemist is door de frequentie van de monstername, welke slechts iedere 2-6 weken plaats heeft gevonden. Echter, de resultaten van de broedval zoals gemeten op de collectoren zouden een meer geïntegreerd beeld over de tijd moeten geven omdat deze continue in het water gehangen hebben. Maar ook deze lieten een laag broedvalsucces zien. Voor zowel de larvenmonsters als de collectoren zijn de monsters vlak onder het wateroppervlak genomen waar de hoogste aantallen larven verwacht worden. De lagere aantallen larven en broedjes in de monsters van de Noordzeeboerderij kunnen deels een reflectie zijn van de lagere dichtheden mossels in de Noordzee maar kunnen ook aangeven dat de gebruikte methodes wellicht minder geschikt zijn voor bemonsteringen in offshore gebieden i.v.m. andere stromingspatronen en mogelijke stratificatie. Stratificatie wordt echter veelal pas waargenomen in de diepere gedeelten van de Noordzee voor, ter hoogte van het Friese Front (Hal et al 2011). Daarnaast blijkt uit eerder onderzoek dat de aantallen larven in de waterkolom niet altijd direct gerelateerd was aan het settlement succes van de mosselen (Capelle, 2018).

Door de infrequente monstername is het lastig om de exacte piek in de larven verspreiding te bepalen. Voor een nadere bepaling van broedval is in eerste instantie een hogere frequentie van monstername wenselijk. De temperatuur rond de Noordzeeboerderij is te vergelijken met de temperatuur in de Oosterschelde en Waddenzee (pers. com J. Capelle) en de data van de Oosterschelde en Waddenzee zouden een indicatie kunnen geven. In beide waterlichamen kwamen de larven in 2018 voor het eerst in het water in week 15 en werden de eerste broedjes geobserveerd in week 21. Aangezien het moment dat de larvenpiek zich voordoet verschilt per jaar en ook per locatie (zie verschil Oosterschelde en Waddenzee), is deze indicatie met de op dit moment beschikbare informatie ontoereikend.

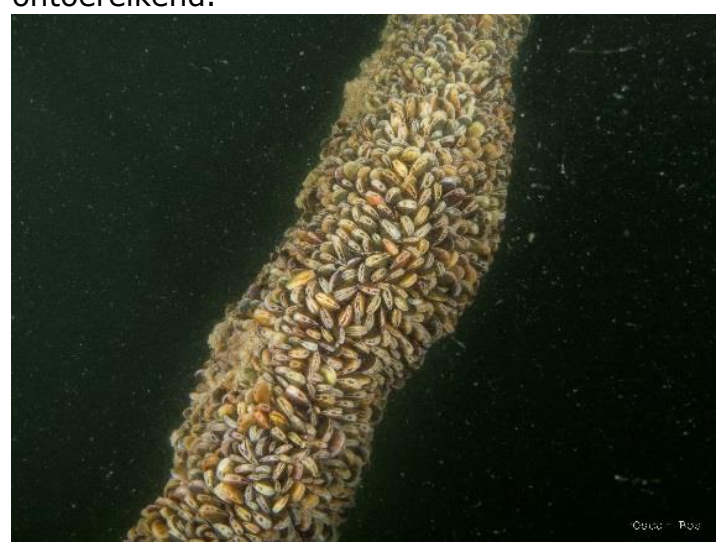

Figuur 4. Mosselbroed op een zeewierkweeksysteem lijn, foto door Oscar Bos. 


\section{Conclusie \& Aanbevelingen}

Aan de hand van de data verzameld in dit onderzoek is het niet mogelijk om het exacte moment van aanwezigheid larven en broedval in 2018 te bepalen. Er zijn vrijwel geen larven aangetroffen in het water, en broedval op de collectoren was aanzienlijk minder in vergelijking met andere waterlichamen (Oosterschelde en Waddenzee). Dit kan deels door de lagere dichtheden van mosselen in de Noordzee komen. Het aantal larven en broed dat gevonden is in de monsters lijken echter niet overeen te komen met de aanzienlijke broedval die is aangetroffen op een zijlijn in de zeewiermodule (figuur 4), een andere conclusie is dat vanwege de frequentie in monstername de piek in aanwezigheid van larven gemist is. In zowel de Oosterschelde als de Waddenzee zijn de eerste larven aangetroffen in week 15 en vond de eerste broedval plaats in week 21. De piek in broedval viel in de Waddenzee eerder dan in de Oosterschelde. Gezien verschillen in larventellingen en broedval per jaar en locatie in de Oosterschelde en Waddenzee lijkt de vergelijkbare watertemperatuur voor de offshore condities en de Oosterschelde \& Waddenzee geen goede indicator voor het bepalen van het moment van de meeste broedval. Voor het afstemmen van het oogstmoment voor zeewier wordt op basis van deze gegevens een conservatieve aanpak geadviseerd met week 20 als uitgangspunt om eventuele aangroei en competitie met mosselen te voorkomen. Hogere frequentie van bemonstering over meerdere jaren, zal een beter beeld geven van het aantal larven en het moment van broedval. Daarbij is het interessant om te bepalen hoe oud de larven zijn (d.m.v. fotograferen en opmeten), waar ze vandaan komen en hoelang ze erover doen. Voor het maken van een voorspelling is het wenselijk om te richten op het komen tot een correlatie op wat er op de Noordzee gebeurt en wat er bijvoorbeeld in de Oosterschelde en de Waddenzee gebeurt. Het broedvalmodel van de Universiteit van Gent zou hierbij ook eventueel ingezet kunnen worden. 


\section{$6 \quad$ Kwaliteitsborging}

Wageningen Marine Research beschikt over een ISO 9001:2008 gecertificeerd kwaliteitsmanagementsysteem (certificaatnummer: 187378-2015-AQ-NLD-RvA). Dit certificaat is geldig tot 15 december 2018. De organisatie is gecertificeerd sinds 27 februari 2001. De certificering is uitgevoerd door DNV Certification B.V. 


\section{Literatuur}

Capelle, J., Blanco, A. \& van Stralen, M. 2017. Invang van mosselzaad in MZI's: results 2017. Wageningen Marine Research, Yerseke.

Capelle, J. J. 2018. Production Efficiency of Mussel Bottom Culture. Wageningen University, 240 $\mathrm{pp}$.

Coolen, J. W. P. 2017. North Sea reefs, benthic biodiversity of artificial and rocky reefs in the southern North Sea. Wageningen University.

Kamermans, P., Soma, K. \& Van Den Burg, S. 2016. Haalbaarheid mosselteelt binnen offshorewindparken in de Nederlandse kustzone. IMARES, Wageningen.

Hal, R. van, Bos O.G. \& Jak R.G. 2011. Noordzee: systeemdynamiek, klimaatverandering, natuurtypen en benthos; Achtergronddocument bij Natuurverkenning 2011. Wageningen, Wettelijke Onderzoekstaken Natuur \& Milieu, WOt-werkdocument 255. 108 blz. 60 fig.; 5 tab.; 177 ref.; 0 bijl. 


\section{Verantwoording}

Rapport C097/18

Projectnummer: $43181001-75$

Dit rapport is met grote zorgvuldigheid tot stand gekomen. De wetenschappelijke kwaliteit is intern getoetst door een collega-onderzoeker en het verantwoordelijk lid van het managementteam van Wageningen Marine Research

Akkoord:

J. Capelle

Onderzoeker

Handtekening:

Datum:

13 december 2018

Akkoord:

Drs. J. Asjes

Manager integratie

Handtekening:

Datum:

13 december 2018 
Wageningen Marine Research

T: +31(0)317480900

E: marine-research@wur.nl

www.wur.nl/marine-research

Visitors address

- Ankerpark 271781 AG Den Helder

- Korringaweg 7, 4401 NT Yerseke

- Haringkade 1, 1976 CP IJmuiden
Wageningen Marine Research is the Netherlands research institute established to provide the scientific support that is essential for developing policies and innovation in respect of the marine environment, fishery activities, aquaculture and the maritime sector.

Wageningen University \& Research is specialised in the domain of healthy food and living environment.

The Wageningen Marine Research vision:

'To explore the potential of marine nature to improve the quality of life.'

The Wageningen Marine Research mission

- To conduct research with the aim of acquiring knowledge and offering advice on the sustainable management and use of marine and coastal areas.

- Wageningen Marine Research is an independent, leading scientific research institute.

Wageningen Marine Research is part of the international knowledge organisation Wageningen UR (University \& Research centre). Within Wageningen UR, nine specialised research institutes of Stichting Wageningen Research (a Foundation) have joined forces with Wageningen University to help answer the most important questions in the domain of healthy food and living environment. 